\title{
Survival analysis of the timing of early marriage among women in Bangladesh: evidence from the 2014 Bangladesh demographic and health survey
}

\author{
MD. AKHTARUL ISLAM ${ }^{A, E}$, SUTAPA DEY BARNA ${ }^{\mathrm{C}-\mathrm{F}}$ \\ ORCID ID: 0000-0003-2396-2168 $\quad$ ORCID ID: 0000-0001-9554-4825
}

Statistics Discipline, Khulna University, Khulna, Bangladesh

A - Study Design, B - Data Collection, C - Statistical Analysis, D - Data Interpretation, E - Manuscript Preparation, F - Literature Search, G - Funds Collection

Summary Background. Early marriage is a common practice in developing countries, with tremendous health implications for women and their newborn children. Few studies have explored teenage marriage in Bangladesh, where the current study was designed to fill this gap.

Objectives. This study aimed to find the socio-economic and demographic factors that influence the timing of early marriage among women in Bangladesh.

Material and methods. A cross-sectional study design was used in our study. Using Bangladesh Demographic and Health Survey 2014 data, we have applied the non-parametric survival analysis technique of the Cox proportional hazards model.

Results. Early marriage was more common in all regions, and this risk was highest in the Rangpur Division (HR $=1.297 ; \mathrm{Cl}: 1.215-1.385$; $p<0.001)$. Women who reside in rural areas married earlier than their counterparts in urban areas ( $\mathrm{HR}=0.918 ; \mathrm{Cl}: 0.883-0.955$; $p<0.001)$. The age at first marriage was directly related to access to media ( $\mathrm{HR}=0.767 ; \mathrm{Cl}: 0.739-0.794 ; p<0.001)$ and education levels, where women should have at least secondary education before marriage. Poor women also married early than upper-class ( $\mathrm{HR}=0.925 ; \mathrm{Cl}: 0.871-0.983)$ and middle-class ( $\mathrm{HR}=0.954 ; \mathrm{Cl}: 0.915-0.994)$ women.

Conclusions. The study's findings may provide some clues to increase the age of Bangladeshi women at first marriage. Region, maternal education, place of residence, wealth index, working status and media access were significantly associated factors with the timing of first marriage among women in Bangladesh.

Key words: marriage, survival analysis, statistical data interpretation, fertility, Bangladesh.

Islam MA, Barna SD. Survival analysis of the timing of early marriage among women in Bangladesh: evidence from the 2014 Bangladesh demographic and health survey. Fam Med Prim Care Rev 2021; 23(4): 429-436, doi: https://doi.org/10.5114/fmpcr.2021.110356.

\section{Background}

The marriage or cohabitation of children below 18 years of age has been extensively documented as a detrimental, discriminatory worldwide practice reflecting gender discrimination and human rights infringement $[1,2]$. Increased attention has been paid to women's well-being and sovereignty throughout the past few decades [3]. Even though child marriage occurs for boys, the prevalence is considerably high for girls, especially in South Asia and sub-Saharan Africa. A young girl may be regarded as an economic burden, and early marriage is used as a tactic by low-income families to cope with financial insecurity, mainly when school fees or transportation costs are high, particularly in many South Asian countries $[4,5]$. Although the percentage of women aged 20 to 24 who married prior to the age of 18 fell from $27 \%$ in 1995 to $21 \%$ in 2015 , the reduction rate in early marriage has been prolonged, and we need a dramatic change of pace to achieve a Sustainable Development Goal (SDG) regarding the elimination of early marriage by 2030 [6].

In Bangladesh, though the legal ages of marriage for males and females are 21 years and 18 years, respectively, many female marriages occur before reaching their legal ages, and this country has the highest rate of marriage involving girls who are less than 15 years of age $[7,8]$. The scenario in Bangladesh shows that early marriage is a product of various cultural, socio-economic and demographic factors, and it also has a positive association with socio-economic development [7]. According to recent statistics on child marriage in southern Asia, the prevalence of child marriage in Bangladesh is the highest at $71 \%$, followed by Nepal (62\%), India (59\%) and Pakistan (50\%) [9]. With inadequate understanding and knowledge about sexual and reproductive life, the major problem with early marriage is the burden of raising children while they are still children themselves [9]. Evidence shows that child pregnancy creates a high risk for both the mother and baby and generates adverse reproductive outcomes, such as unwanted pregnancies, mistimed pregnancies, abortion, miscarriage, anemia, etc. $[9,10]$. Preterm delivery, delivery of low birth weight babies, fetal mortality, as well as physical, sexual and emotional violence within the marriage are also unfavorable consequences of early marriage for young women [11-14]. It is reported that girls between the ages of 15-19 are twice as likely to die of pregnancy-related complications [15]. Thus, child marriage has severe impacts on girls' education, accomplishment, psychological well-being, human rights, and economic survival, and also influences the acceleration of demise of the respondent and her child [16-18]. Though early marriage is a common issue in Bangladesh and other developing countries in Asia and Africa, it is one of the most critical factors in population dynamics, as it affects fertility, mortality and women's and children's health [19]. Several studies have been conducted on identifying the factors associated with age at first marriage and showed that the disparities of social, economic, demographic, cultural, religious and public health factors affect marriage timing $[4,16]$. 


\section{Objectives}

This paper's goal was to raise awareness of the situation on timing and patterns of age at first marriage among women of reproductive age in Bangladesh. Survival analysis techniques were used to estimate early marriage time and determine the associated factors that are appropriate and provide more information and reliable estimates with measurable precision.

\section{Material and methods}

\section{Data source}

Secondary sources of data were obtained from BDHS 2014 The survey used a sampling frame from the list of Enumeration Areas (EAs) of the 2011 Population and Housing Census of the People's Republic of Bangladesh, provided by the Bangladesh Bureau of Statistics (BBS). The Primary Sampling Unit (PSU) for the survey is an EA created to have an average of about 120 households. The survey is based on a two-stage stratified sample of households. In the first stage, 600 EAs were selected with a probability proportional to the EA size, with 207 EAs in urban areas and 393 in rural areas. In the second stage of sampling, a systematic sample of 30 households on average was selected per EA. The survey selected 18,000 residential households, which were expected to result in completed interviews with about 18,000 ever-married women [20].

\section{Statistical analysis}

At the univariate level, frequency distributions were carried out for different covariates, and at the bivariate level, the log-rank chi-square was used to test for equality of the survival times. The log-rank chi-square was used to test if there is a significant difference between ages at first marriage among women of different socio-economic characteristics. The level of significance was set at 0.05 , which is at a confidence interval of $95 \%$. After that, the Cox proportional hazards model was used to predict the strength of the relationship between the selected independent variables and timing of marriage. SPSS (version 23) was used at the univariate and bivariate level, and programming language $\mathrm{R}$ (version 3.6.3) was used for the log-rank test, Kaplan-Meier test and Cox proportional hazards model.

\section{Variables}

The variable age at first marriage was categorized into two categories: early marriage (less than 18 years of age) and not early marriage (greater or equal to 18 years of age). The dependent variable of our study was "Early Marriage", and it was categorized as Yes (marriage before 18 years of age) and No (marriage after 18 years of age). For independent variables, we considered the critical determinants of early marriage, which were region, place of residence, wealth index, respondent's education level, husband's education level, access to mass media, respondent's current working status, religion and BMI.

\section{Cox Proportional Hazards Model}

Let $X=X_{1}, X_{2}, \ldots, X_{p}$ be the $P \times 1$ vector of covariates, which is associated with $P \times 1$ vector of regression coefficients $B=\left(B_{1^{\prime}}, B_{2^{\prime}}\right.$ $\left.\ldots, B_{p}\right)$. Suppose that $T$ be a survival time in the presence of the covariate, and $h_{0}(t)$ is the hazard function at the time point $t$ in the absence of the covariate known as the baseline hazard function. Now under the Cox proportional hazard model, the hazard function in the presence of the covariate can be expressed as $h(t)=h_{0}(t) c(x)$, where $c(x)$ is a positive valued function that has a known parametric form such as $c(x)=\exp \left(B^{\prime} x\right)$.

The principles of the Cox proportional hazards model usually create a link between the survival time of an individual and corresponding associated covariates [21, 22]. It explores the relationship between the event of interest and several explanatory variables. Finally, the Cox model involves examining the coefficients for each explanatory variable and getting the required result. In this study, $t_{i j}$ represents our event of interest, the birth interval corresponding to the $j^{\text {th }}$ child of the $i^{\text {th }}$ mother of the cluster. Let $X_{i j}=\left(X_{i j 1}, X_{i j 2}, \ldots, X_{i j p}\right)$ is the associated $p$-dimensional covariate vector $\left(i=1, \ldots n ; j=1, \ldots, m_{i}\right)$. The hazard function for the birth interval $t_{i j}$ under the Cox proportional hazards model can be written as: $h\left(t_{i j}\right)=h_{0}\left(t_{i j}\right) \exp \left(B^{\prime} x_{i j}\right)$.

\section{Ethical approval}

We used a secondary dataset from the Demographic and Health Surveys (DHS) Program website (https://dhsprogram. $\mathrm{com} /$ data/). No ethics approval was required for this dataset.

\section{Results}

\section{Uni-variate analysis}

The result is based on 17,342 valid observations of all over married women aged 15-49 in 2014 BDHS data. Table 1 shows the pattern of the distribution and the study of the socio-demographic characteristics. From Table 1, we can review the percentage distribution of selected variables. We can see that among seven divided regions, the highest number of respondents belonged to the Dhaka division (17.4\%), and the lowest number of respondents was from the Sylhet division (11.8\%). The percentages corresponding to the Chittagong, Khulna, Rajshahi, Rangpur and Barisal divisions were 16.0\%, 14.4\%, 14.2\%, $14.2 \%$ and $12.1 \%$, respectively. About $65.7 \%(11,401)$ were from the rural area, and $34.3 \%(5,941)$ were from the urban area, as village areas covered most of Bangladesh. On the other hand, the wealth index showed that middle-class respondents had the highest frequency, i.e. $41.5 \%(7,189)$, whereas $37.5 \%(6,499)$ of the respondents were lower-class, and $21.1 \%(3,654)$ of the respondents were upper-class. If we look at the respondents' education level, $37.8 \%(6,559)$ of the respondents completed secondary level, $29.3 \%(5,079)$ of the respondents completed primary level, $23.4 \%(4,061)$ of the respondents were illiterate, and only $9.5 \%(1,643)$ of the respondents completed higher education. Table 1 also shows the respondents' partners' education level, where $29.6 \%(5,134)$ of the partners completed secondary level, $27.3 \%(4,740)$ completed primary level, $14.9 \%(2,576)$ completed higher education, and a large portion, i.e. $28.2 \%$ $(4,892)$, were illiterate. On the other hand, the percentage of respondents who had access to mass media was higher, i.e. $61.3 \%(10,639)$, than those who had no access to it, which was $38.7 \%(6,703)$. Among all the respondents, $68.4 \%$ (11 858) did not work, and only $31.6 \%(5,484)$ of the respondents worked. In this study, $90.2 \%(15,650)$ respondents were Muslim, whereas $9.8 \%(1,692)$ of the respondents were non-Muslim. Moreover, $57.4 \%(9,958)$ of the respondents were of normal healthy condition, but $24.1 \%(4,181)$ of the respondents were overweight, and $18.5 \%(3,203)$ of the respondents were underweight.

\section{Bivariate analysis}

Table 2 represents the bivariate analysis results for different covariates level by early marriage status. It can be seen that women in the Rangpur region had the highest early marriage rate, i.e. 2,063 (83.5\%), whereas the women from the Sylhet region had the lowest marriage rate of about 1,310 (63.8\%). Meanwhile, rural women had a higher early marriage rate of 8,945 $(78.5 \%)$. On the contrary, the women of urban areas showed lower mortality, i.e. 4,322 (72.7\%). Wealth status revealed that low-income families had a higher early marriage rate of 5,136 $(79 \%)$, whereas women from a wealthy family had a marriage rate of $2,643(72.3 \%)$. The respondents who completed sec- 


\begin{tabular}{|c|c|c|c|}
\hline Covariates & Category & Frequency & $(\%)$ \\
\hline \multirow[t]{7}{*}{ Region } & Barisal & 2,090 & 12.1 \\
\hline & Chittagong & 2,769 & 16.0 \\
\hline & Dhaka & 3,011 & 17.4 \\
\hline & Khulna & 2,495 & 14.4 \\
\hline & Rajshahi & 2,454 & 14.2 \\
\hline & Rangpur & 2,471 & 14.2 \\
\hline & Sylhet & 2,052 & 11.8 \\
\hline \multirow[t]{2}{*}{ Residence } & urban & 5,941 & 34.3 \\
\hline & rural & 11,401 & 65.7 \\
\hline \multirow[t]{3}{*}{ Wealth Index } & lower-class & 6,499 & 37.5 \\
\hline & middle-class & 7,189 & 41.5 \\
\hline & upper-class & 3,654 & 21.1 \\
\hline \multirow[t]{4}{*}{ Respondent's education level } & no education & 4,061 & 23.4 \\
\hline & primary & 5,079 & 29.3 \\
\hline & secondary & 6,559 & 37.8 \\
\hline & higher & 1,643 & 9.5 \\
\hline \multirow[t]{4}{*}{ Husband's education level } & no education & 4,892 & 28.2 \\
\hline & primary & 4,740 & 27.3 \\
\hline & secondary & 5,134 & 29.6 \\
\hline & higher & 2,576 & 14.9 \\
\hline \multirow[t]{2}{*}{ Access to mass media } & no & 6,703 & 38.7 \\
\hline & yes & 10,639 & 61.3 \\
\hline \multirow[t]{2}{*}{ Respondent currently working } & no & 11,858 & 68.4 \\
\hline & yes & 5,484 & 31.6 \\
\hline \multirow[t]{2}{*}{ Religion } & non-Muslim & 1,692 & 9.8 \\
\hline & Muslim & 15,650 & 90.2 \\
\hline \multirow[t]{3}{*}{ BMI } & underweight & 3,203 & 18.5 \\
\hline & normal & 9,958 & 57.4 \\
\hline & overweight & 4,181 & 24.1 \\
\hline
\end{tabular}

\begin{tabular}{|c|c|c|c|c|}
\hline \multirow[t]{2}{*}{ Covariates } & \multirow[t]{2}{*}{ Category } & \multicolumn{3}{|l|}{ Survival status } \\
\hline & & $\begin{array}{l}\text { Early marriage } n(\%) \\
\leq 17 \text { years }\end{array}$ & $\begin{array}{l}\text { Not early marriage } n(\%) \\
\geq 18 \text { years } \\
\end{array}$ & Total $n(\%)$ \\
\hline \multirow[t]{7}{*}{ Region } & Barisal & $1,648(78.9)$ & $442(21.1)$ & $2,090(12.05)$ \\
\hline & Chittagong & $1,966(71.0)$ & $803(29.0)$ & 2,769 (15.97) \\
\hline & Dhaka & $2,249(74.7)$ & $762(25.3)$ & $3,011(17.36)$ \\
\hline & Khulna & $1,995(80.0)$ & $500(20.0)$ & 2,495 (14.39) \\
\hline & Rajshahi & $2,036(83.0)$ & $418(17.0)$ & $2,454(14.15)$ \\
\hline & Rangpur & $2,063(83.5)$ & $408(16.5)$ & 2,471 (14.25) \\
\hline & Sylhet & $1,310(63.8)$ & $742(36.2)$ & $2,052(11.83)$ \\
\hline \multirow[t]{2}{*}{ Residence } & urban & $4,322(72.7)$ & $1,619(27.3)$ & $5,941(34.26)$ \\
\hline & rural & $8,945(78.5)$ & $2,456(21.5)$ & $11,401(65.74)$ \\
\hline \multirow[t]{3}{*}{ Wealth Index } & lower-class & $5,136(79.0)$ & $1363(21.0)$ & 6,499 (37.48) \\
\hline & middle-class & $5,488(76.3)$ & $1,701(23.7)$ & 7,189 (41.45\%) \\
\hline & upper-class & $2,643(72.3)$ & $1,011(27.7)$ & $3,654(21.07)$ \\
\hline \multirow[t]{4}{*}{ Respondent's education level } & no education & $3,076(75.7)$ & $985(24.3)$ & $4,061(23.42)$ \\
\hline & primary & $3,891(76.6)$ & $1,188(23.4)$ & $5,079(29.29)$ \\
\hline & secondary & $5,069(77.3)$ & $1,490(22.7)$ & 6,559 (37.82) \\
\hline & higher & $1,231(74.9)$ & $412(25.1)$ & $1,643(9.47)$ \\
\hline \multirow[t]{4}{*}{ Husband's education level } & no education & $3,774(77.1)$ & $1,118(22.9)$ & $4,892(28.21)$ \\
\hline & primary & $3,623(76.4)$ & $1,117(23.6)$ & $4,740(27.33)$ \\
\hline & secondary & $3,931(76.6)$ & $1,203(23.4)$ & $5,134(29.60)$ \\
\hline & higher & $1,939(75.3)$ & $637(24.7)$ & $2,576(14.85)$ \\
\hline
\end{tabular}




\begin{tabular}{|c|c|c|c|c|}
\hline \multirow[t]{2}{*}{ Covariates } & \multirow[t]{2}{*}{ Category } & \multicolumn{3}{|l|}{ Survival status } \\
\hline & & $\begin{array}{l}\text { Early marriage } n(\%) \\
\leq 17 \text { years }\end{array}$ & $\begin{array}{l}\text { Not early marriage } n(\%) \\
\geq 18 \text { years }\end{array}$ & Total $n(\%)$ \\
\hline \multirow[t]{2}{*}{ Respondent currently working } & no & $9,018(76.0)$ & $2,840(24.0)$ & $11,858(68.38)$ \\
\hline & yes & $4,249(77.5)$ & $1,235(22.5)$ & $5,484(31.62)$ \\
\hline \multirow[t]{2}{*}{ Religion } & non-Muslim & $1,293(76.4 \%)$ & $399(23.6)$ & $1,692(9.76)$ \\
\hline & Muslim & $11,974(76.5 \%)$ & $3,676(23.5)$ & $15,650(90.24)$ \\
\hline \multirow[t]{2}{*}{ Access to mass media } & no & $5,500(82.1 \%)$ & $1,203(17.9)$ & $6,703(38.65)$ \\
\hline & yes & $7,767(73.0 \%)$ & $2872(27.0)$ & $10,639(61.35)$ \\
\hline \multirow[t]{3}{*}{ BMI } & underweight & $2,486(77.6 \%)$ & $717(22.4)$ & $3,203(18.47)$ \\
\hline & normal & 7,639 (76.7\%) & $2,319(23.3)$ & $9,958(57.42)$ \\
\hline & overweight & $3,142(75.1 \%)$ & $1,039(24.9)$ & $4,181(24.11)$ \\
\hline
\end{tabular}

ondary education had an early marriage rate of 5,069 (77.3\%), and higher educated respondents had an early marriage rate of $1,231(74.9 \%)$. On the other hand, working respondents had the highest marriage rate of 4,249 $(77.5 \%)$, and the non-working respondents had a marriage rate of $9,018(76 \%)$. Table 2 also shows that Muslim respondents' early marriage rate was 11,974 (76.5\%), and non-Muslim respondents' rate was 1,293 (76.4\%). The marriage rate of women who had access to any mass media was $7,767(73 \%)$, and the marriage rate of those not having any access was 5,500 (82.1\%). Also, early married respondents with underweight and overweight status were (2486) $77.6 \%$, and (3142) $75.1 \%$, respectively.

\section{Kaplan-Meier (KM) test and log-rank test}

KM survival estimates and the log-rank test for early marriage age by covariates are shown in Table 3. The log-rank chi-square was used at the bivariate level to test for equality of the survival times. These indicators help us test if there is a significant difference between ages at early marriage among women of different socio-economic characteristics. Table 3 reveals that the mean marriage age for females who lived in the Sylhet division and urban areas, those who were Muslims, had media access and belonged to wealthy families were greater than those for other categories in each covariate. Apparently, the mean marriage age for females with secondary education was 19.92 years, which is the least mean marriage age compared to the other levels. Husbands with secondary education had the least mean marriage age, i.e. 20.61 years, compared with other males' educational levels. Females in the underweight group had the highest marriage age, i.e. 22.29 years. On the other hand, working women had the least mean marriage age (19.14 years) compared to non-working women (22.85 years).

The association of the individual factors on time to early marriage was tested using the log-rank test. The results from Table 3 show that the time to early marriage significantly differed by region, place of residence, access to mass media, respondents' working status, wealth index and BMI. Meanwhile, the husband's education level was significant at $10 \%$, and other factors did not significantly differ in survival functions. Figure 1 shows the survival curves of females' marriage age for each significant covariate.

\begin{tabular}{|c|c|c|c|c|c|}
\hline Covariates & Category & Mean survival time & Chi-square & Df & $p$ \\
\hline \multirow[t]{7}{*}{ Region } & Barisal & 18.56 & \multirow[t]{7}{*}{586} & \multirow[t]{7}{*}{6} & \multirow[t]{7}{*}{0.000} \\
\hline & Chittagong & 21.58 & & & \\
\hline & Dhaka & 22.01 & & & \\
\hline & Khulna & 19.53 & & & \\
\hline & Rajshahi & 18.29 & & & \\
\hline & Rangpur & 19.19 & & & \\
\hline & Sylhet & 27.35 & & & \\
\hline \multirow[t]{2}{*}{ Residence } & urban & 22.63 & \multirow[t]{2}{*}{69.2} & \multirow[t]{2}{*}{1} & \multirow[t]{2}{*}{0.000} \\
\hline & rural & 21.99 & & & \\
\hline \multirow[t]{2}{*}{ Religion } & non-Muslim & 20.19 & \multirow[t]{2}{*}{1} & \multirow[t]{2}{*}{1} & \multirow[t]{2}{*}{0.3} \\
\hline & Muslim & 22.67 & & & \\
\hline \multirow[t]{3}{*}{ Wealth Index } & lower-class & 19.47 & \multirow[t]{3}{*}{62.6} & \multirow[t]{3}{*}{2} & \multirow[t]{3}{*}{0.000} \\
\hline & middle-class & 22.75 & & & \\
\hline & upper-class & 22.77 & & & \\
\hline \multirow[t]{4}{*}{ Respondent's educational level } & no education & 21.71 & \multirow[t]{4}{*}{4.3} & \multirow[t]{4}{*}{3} & \multirow[t]{4}{*}{0.2} \\
\hline & primary & 22.63 & & & \\
\hline & secondary & 19.92 & & & \\
\hline & higher & 21.99 & & & \\
\hline \multirow[t]{4}{*}{ Husband's education level } & no education & 21.27 & \multirow[t]{4}{*}{6.4} & \multirow[t]{4}{*}{3} & \multirow[t]{4}{*}{0.09} \\
\hline & primary & 22.68 & & & \\
\hline & secondary & 20.61 & & & \\
\hline & higher & 21.86 & & & \\
\hline
\end{tabular}




\begin{tabular}{|c|c|c|c|c|c|}
\hline Covariates & Category & Mean survival time & Chi-square & Df & $p$ \\
\hline \multirow[t]{2}{*}{ Access to mass media } & no & 19.07 & \multirow[t]{2}{*}{233} & \multirow[t]{2}{*}{1} & \multirow[t]{2}{*}{0.000} \\
\hline & yes & 23.93 & & & \\
\hline \multirow[t]{2}{*}{ Respondent currently working } & no & 22.85 & \multirow[t]{2}{*}{8.8} & \multirow[t]{2}{*}{1} & \multirow[t]{2}{*}{0.003} \\
\hline & yes & 19.14 & & & \\
\hline \multirow[t]{3}{*}{$\mathrm{BMI}$} & under & 22.29 & \multirow[t]{3}{*}{9.5} & \multirow[t]{3}{*}{2} & \multirow[t]{3}{*}{0.009} \\
\hline & normal & 21.43 & & & \\
\hline & over & 20.94 & & & \\
\hline
\end{tabular}

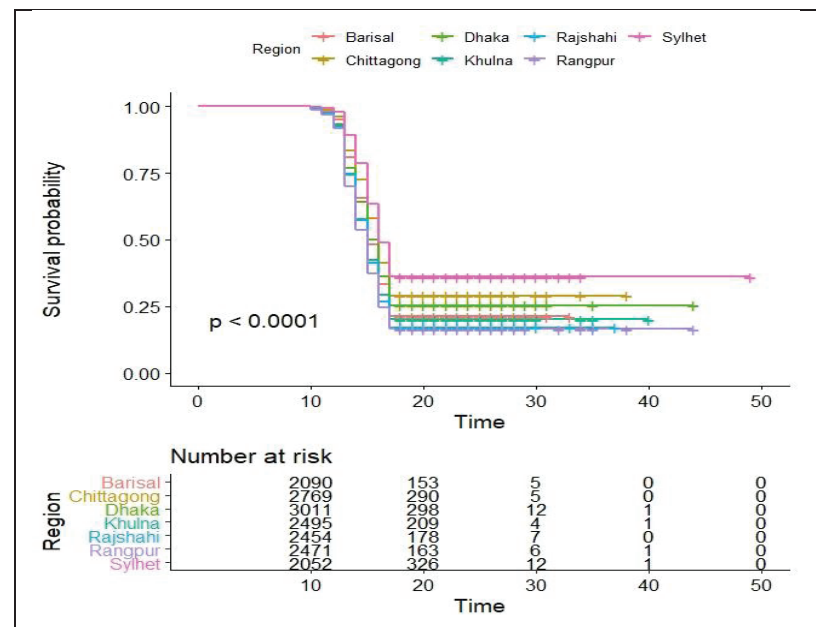

(a) Survival function of region
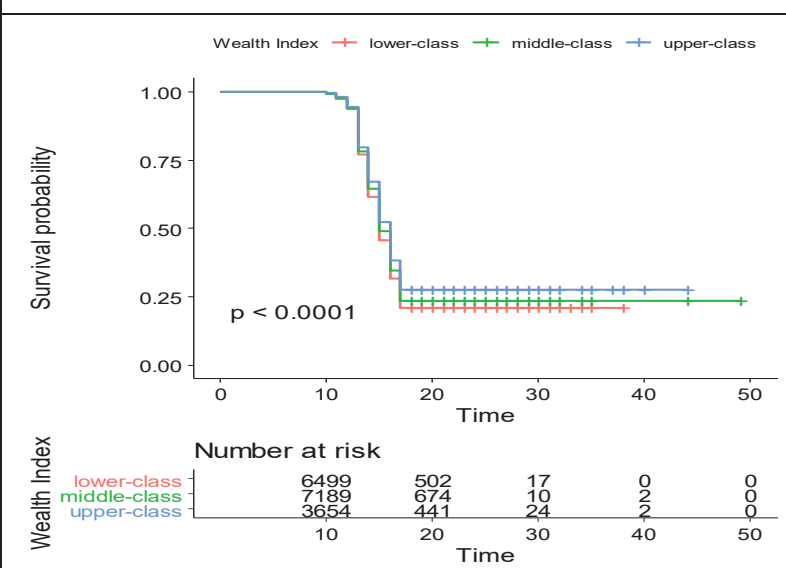

(c) Survival function of wealth index

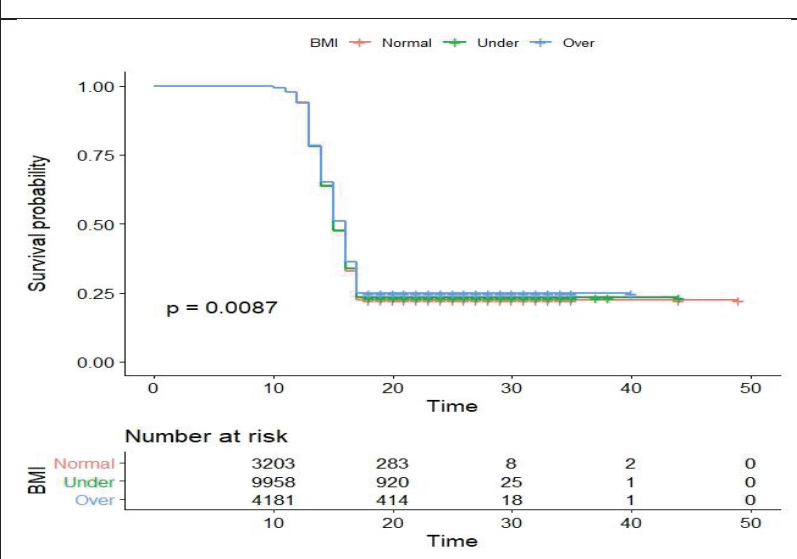

(e) Survival function of respondent's BMI

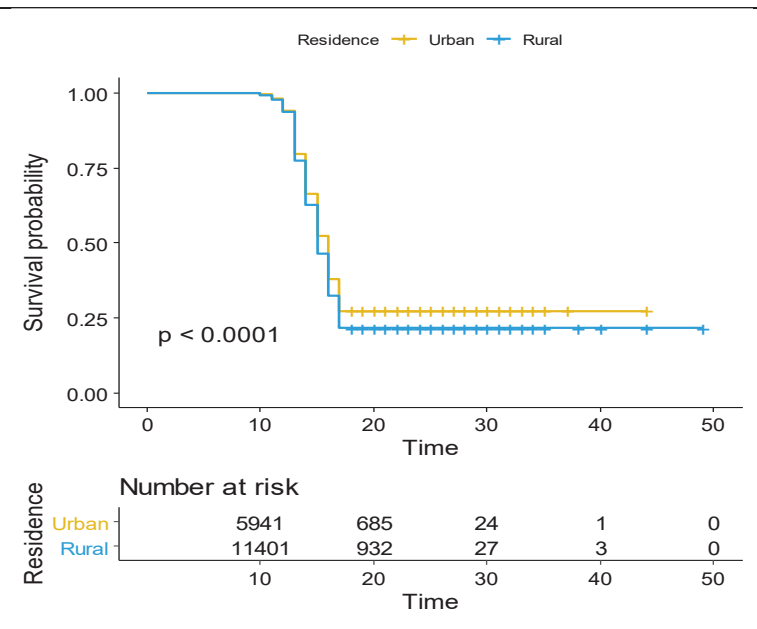

(b) Survival function of residence
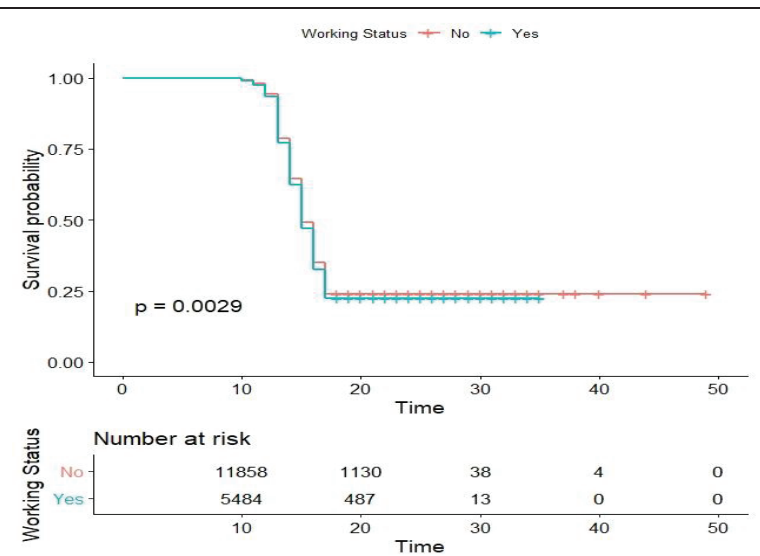

(d) Survival function of working status

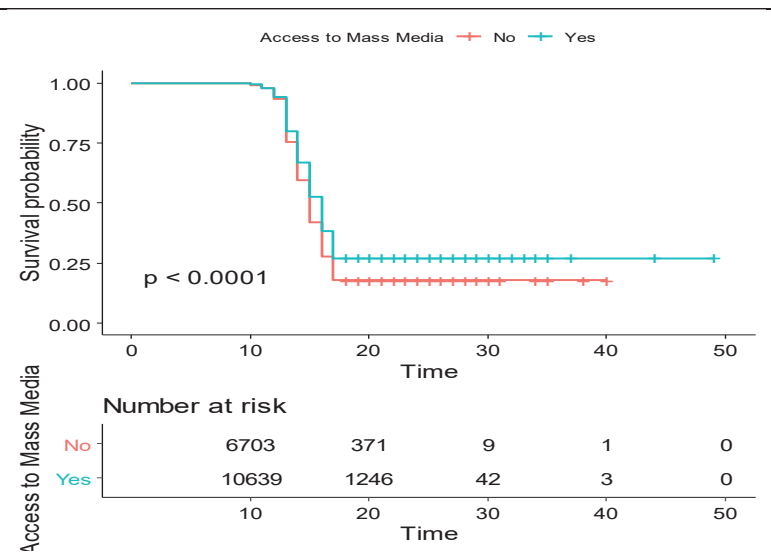

(f) Survival function of access to mass media 
Figure $1(\mathrm{a})$ and 1 (b) show that as the $p$-value $(<0.001)$ was less than 0.05 , there was significant evidence of a difference in survival times for all divisions, as well as the place of residences. The survival probability was higher for the Sylhet division and lower for the Rajshahi division, whereas the survival probability was higher for urban areas and lower for the rural areas. From Table 3, the estimated mean time until death was 19.47 years for a lower-class family, 22.75 years for a middle-class family, and 22.77 years for an uppwe-class family. Thus, the survival probabilities were higher for an upper-class family and lower for a [ower-class family [Figure 1(c)]. Similarly, non-working respondents had the highest survival probabilities and were the lowest in respondents who worked [Figure $1(\mathrm{~d})$ ]. Here, in both cases, the $p$-values were less than 0.05 , which concluded that there was significant evidence of differences in survival time. As the $p$-value (0.0087) was less than 0.05 , there was significant evidence of a difference in survival times for the type of BMI [Figure 1(e)]. Figure 1(f) also shows that there was significant ( $p$ $<0.001$ ) evidence of the differences in access to media, where the survival probabilities were higher for women having media access and lower for those who had no access.

\section{Cox regression analysis}

Using the hazard ratios, a Cox proportional hazard model provides information about the distribution of specific covariates. Table 4 shows the Cox proportional hazards model of the association between the timing of first marriage and background characteristics.
The result indicates that the region had a significant effect on time to early marriage. The hazard of early marriage was highest in the Rangpur division and lowest in the Sylhet division. In this regard, Rangpur had a 30\% higher and Sylhet had a 35\% lower risk of early marriage compared to the Barisal division. The risk of early marriage was $15 \%$ lower for women in the Chittagong division, $17 \%$ higher in Khulna and $25 \%$ higher in the Rajshahi division than for women in the Barisal division. Meanwhile, the risk of early marriage was not statistically significant for women in the Dhaka division. Moreover, the place of residence played a significant role in the time to early marriage. Here, respondents living in urban areas had a $9 \%$ lower hazard of early marriage than those who lived in rural areas. The risk of early marriage was $7 \%$ higher for women with secondary education compared to women with no education, but primary and higher education levels were not statistically significant. Thus, the risk of getting married did not decline as the level of education increased. On the other hand, no significant relationship existed between the timing of marriage and the respondents' partners' education, whereas the wealth index of the respondents had a significant effect on early marriage at a $10 \%$ level of significance. Women who belonged to a middle-class family had a $5 \%$ lower risk, and upper-class families had a $7 \%$ lower risk of early marriage compared to those who belonged to a lower-class family. The result also indicates that those whose families had access to mass media had a $23 \%$ lower risk of early marriage than those who had no access to mass media. Here, media access also significantly affected early marriage, whereas no significant result was found for religion, the respondents' working status and BMI.

\begin{tabular}{|c|c|c|c|c|}
\hline Variables & Category & Coefficient & HR & $p$ [CI (95\%)] \\
\hline \multirow{7}{*}{ Region } & Barisal (ref.) & & & \\
\hline & Chittagong & -0.160 & 0.852 & $0.000[0.797-0.911]^{* *}$ \\
\hline & Dhaka & 0.021 & 1.021 & $0.533[0.956-1.091]$ \\
\hline & Khulna & 0.160 & 1.173 & $0.000[1.098-1.253]^{* *}$ \\
\hline & Rajshahi & 0.224 & 1.251 & $0.000[1.171-1.336]^{* *}$ \\
\hline & Rangpur & 0.260 & 1.297 & $0.000[1.215-1.385]^{* *}$ \\
\hline & Sylhet & -0.423 & 0.655 & $0.000[0.602-0.705]^{* *}$ \\
\hline \multirow[t]{2}{*}{ Residence } & rural (ref.) & & & \\
\hline & urban & -0.085 & 0.918 & $0.000[0.883-0.955]^{* *}$ \\
\hline \multirow[t]{2}{*}{ Religion } & Muslim (ref.) & & & \\
\hline & non-Muslim & -0.017 & 0.983 & 0.564 [0.928-1.042] \\
\hline \multirow[t]{4}{*}{ Respondent's education level } & no education (ref.) & & & \\
\hline & primary & 0.028 & 1.028 & 0.270 [0.979-1.081] \\
\hline & secondary & 0.069 & 1.071 & $0.010[1.016-1.130]^{* *}$ \\
\hline & higher & 0.041 & 1.043 & $0.330[0.959-1.134]$ \\
\hline \multirow[t]{4}{*}{ Husband's education level } & no education (ref.) & & & \\
\hline & primary & -0.028 & 1.028 & 0.257 [0.927-1.021] \\
\hline & secondary & -0.042 & 0.958 & 0.117 [0.909-1.011] \\
\hline & higher & -0.020 & 0.981 & $0.602[0.912-1.056]$ \\
\hline \multirow[t]{2}{*}{ Respondent currently working } & no (ref.) & & & \\
\hline & yes & -0.011 & 0.89 & $0.055[0.795-0.927]^{*}$ \\
\hline \multirow[t]{3}{*}{ Wealth Index } & loer-class (ref.) & & & \\
\hline & \begin{tabular}{|l|} 
middle-class \\
\end{tabular} & -0.047 & 0.954 & $0.026[0.915-0.994]^{*}$ \\
\hline & upper-class & -0.078 & 0.925 & $0.012[0.871-0.983]^{*}$ \\
\hline \multirow[t]{2}{*}{ Access to mass media } & no (ref.) & & & \\
\hline & yes & -0.266 & 0.767 & $0.000[0.739-0.794]^{* *}$ \\
\hline \multirow[t]{3}{*}{ BMI } & normal (ref.) & & & \\
\hline & under & 0.030 & 1.031 & 0.195 [0.985-1.079] \\
\hline & over & -0.016 & 0.984 & $0.462[0.942-1.028]$ \\
\hline
\end{tabular}

** Significant at a level of $5 \%, *$ significant at a level of $10 \%, \mathrm{HR}$ - hazard rate. 


\section{Discussion}

Previously, in Bangladesh, most family members, especially males, made all important decisions concerning the female, including who and when they should marry. Nowadays, this has changed, and women are making their own decisions about whom and when to marry. The different triggering key issues of early marriage in Bangladesh have been demonstrated in this study. This study has used survival analysis techniques to study women's time to first marriage using the 2014 Bangladesh Demographic and Health Survey data. Univariate analysis, log-rank test and Cox proportional hazards regression analysis were used to estimate and investigate the differences and early marriage timing determinants. The obtained results suggested that region, place of residence, women's education level, wealth index and mass media were significant determinants of early marriage in Bangladeshi women.

The log-rank test also showed that the different levels of regions, place of residence, educational levels of the husband, wealth index of the family, BMI, access to mass media and respondent's working status were all risk factors of timing of the first marriage. A similar study with Kaplan-Meier and log-rank tests showed that the mean of marriage age for females and males who lived in urban areas, being employed, having more siblings and having more income were greater than those for other categories in each covariate [23].

Although the age of marriage is generally increasing at a low pace, early marriage is still widely practiced in Bangladesh. This research explores regional differences in age at marriage among women in Bangladesh. Divisions have a significant effect on age at first marriage in Bangladesh [24]. Similar studies based in $\mathrm{Ni}$ geria and Uganda also reveal that district of residence played a significant role among women on their age at first marriage $[25,26]$. The places of residence partially explain the process of socialization as there is an impact of socio-economic variations in rural and urban areas, which also effects the timing of marriage. Findings from the current study reveal that the mean age at marriage was significantly higher in urban than rural areas, and early marriage was found to be widespread there. Studies with similar findings show that rural families encourage their daughters for early marriage to get potential husbands and avoid the threat of kidnapping on the way to school [27-29].

Although no significant result was found between religion and marriage timing in this study, socio-demographics, cultural norms and traditional beliefs were reflected by Muslim and rural residents [5, 24]. Women from rural areas are more likely to reflect the conventional behavior of early marriage as, in terms of education and economic status, rural areas are more disadvantaged. Again, females in both middle- and upper-class families got married at a higher interval than poor class families. Some of the earlier studies conducted in Bangladesh, Hong Kong and a few other developing countries showed consistent results with these findings $[7,17,29-31]$. Using DHS data from
54 developing countries, a recent study illustrates that girls living in poor families were two times more likely to marry before the age of 18 than those from upper-class family background households, and girls living in rural areas were at a greater risk of early marriage than those in urban areas [28].

It is well known that there is an association between education and age at first marriage worldwide. In the current study, we observed that women with secondary educated were more aware of the harmful effects of an early marriage than illiterate women. Meanwhile, females' level of education did not show any evident association with the timing of marriage. Several studies have shown a significant negative relationship between education and fertility [7, 27].

Moreover, we found that poverty has a severe effect on the timing of marriage. Some scholars also stated that employed females got married at later ages compared to unemployed females. In this study, women's working status showed a significant result in the log-rank test and Cox regression analysis. A similar study showed that women's economic independence is mainly responsible for the delay in the timing of marriage, and it had a significant effect $[3,29,32,33]$. Along with this, it was also observed that females who were exposed to media made the decision not to get married early compared to those not exposed to media. This finding was was in line with an earlier study stating that media helped create awareness among women about the adverse effects of an early marriage [34-36].

\section{Conclusions}

This study has demonstrated that regional difference is the most important factor relating to a female's age at first marriage. Education is also an essential determinant of the timing of marriage. Women should have at least secondary education before being wed. The strong association between wealth index, working status and child marriage also suggests that economically disadvantaged girls should be provided sufficient help to increase their level of education. Besides formal education, women must have access to informal education. It can increase social awareness and avoid the consequences of early marriage. In this regard, access to media can play a vital role.

Moreover, in Bangladesh, rural girls should be encouraged and given the privileges to be highly educated. The ordinance of the legal age of marriage needs to be strictly followed for the betterment of women's health as well as to ensure the wellbeing of their children. Though there is a significant change in people's mindsets regarding this issue, the government should still take necessary actions in this regard to reduce the mortality rate in childbirth and ensure better living conditions.

Acknowledgments. We would also like to show our gratitude to the Demographic and Health Surveys (DHS) Program for providing data. The authors are eternally grateful to the authors of the different articles used in this study.

Source of funding: This work was funded from the authors' own resources.

Conflicts of interest: The authors declare no conflicts of interest.

\section{References}

1. Uchitel J, Alden E, Bhutta ZA, et al. The rights of children for optimal development and nurturing care. Pediatrics 2019; 144(6): e20190487.

2. Arthur M, Earle A, Raub A, et al. Child marriage laws around the world: minimum marriage age, legal exceptions, and gender disparities. J Women Polit Policy 2018; 39(1): 51-74.

3. Yaya S, Odusina EK, Bishwajit G. Prevalence of child marriage and its impact on fertility outcomes in 34 sub-Saharan African countries. BMC Int Health Hum Rights 2019; 19(1): 1-11.

4. Bajracharya A, Psaki S, Sadiq M. Child marriage, adolescent pregnancy and school dropout in South Asia. Kathmandu: UNICEF Regional Office for South Asia; 2019.

5. Kamal SM, Hassan CH, Alam GM, et al. Child marriage in Bangladesh: trends and determinants. J Biosoc Sci 2015; 47(1): 120-139.

6. UNICEF. New global estimates of child marriage. New York: UNICEF; 2018. 
7. Kamal SM. Socioeconomic determinants of age at first marriage of the ethnic tribal women in Bangladesh. Asian Popul Stud 2011; 7(1): 69-84.

8. UNICEF. Ending child marriage: progress and prospects. UNICEF; 2014.

9. Godha D, Hotchkiss DR, Gage AJ. Association between child marriage and reproductive health outcomes and service utilization: a multicountry study from South Asia. J Adolesc Health 2013; 52(5): 552-558.

10. Nasrullah M, Muazzam S, Bhutta ZA, et al. Girl child marriage and its effect on fertility in Pakistan: findings from Pakistan Demographic and Health Survey, 2006-2007. Matern Child Health J 2014; 18(3): 534-543.

11. Santhya K. Early marriage and sexual and reproductive health vulnerabilities of young women: a synthesis of recent evidence from developing countries. Curr Opin Obstet Gynecol 2011; 23(5): 334-339.

12. Hong Le MT, Tran TD, Nguyen HT, et al. Early marriage and intimate partner violence among adolescents and young adults in Viet Nam. J Interpers Violence 2014; 29(5): 889-910.

13. Erulkar A. Early marriage, marital relations and intimate partner violence in Ethiopia. Int Perspect Sex Reprod Health 2013; 39(1): 6-13.

14. Rahman M, Hoque MA, Mostofa MG, et al. Association between adolescent marriage and intimate partner violence: a study of young adult women in Bangladesh. Asia Pac J Public Health 2014; 26(2): 160-168.

15. Malhotra A, Warner A, McGonagle A, et al. Solutions to end child marriage. Washington (DC): International Center for Research on Women; 2011.

16. Walker J-A. Early marriage in Africa - trends, harmful effects and interventions. Afr J Reprod Health 2012; 16(2): 231-240.

17. Delprato M, Akyeampong K, Dunne M. Intergenerational education effects of early marriage in Sub-Saharan Africa. World Development 2017; 91: 173-192.

18. Wodon Q. Child marriage and education in Sub-Saharan Africa. Washington: World Bank; 2015.

19. Streatfield PK, Kamal N, Ahsan KZ, et al. Early marriage in Bangladesh: not as early as it appears. Asian Population Studies 2015; 11(1): 94-110.

20. National Institute of Population Research and Training, Mitra and Associates, and ICF International. Bangladesh demographic and health survey 2014: key indicators. Dhaka, Rockville (MD): NIPORT, Mitra and Associates, ICF International; 2015.

21. Cox DR. Regression models and life-tables. J R Stat Soc Ser B 1972; 34(2): 187-202.

22. Lane WR, Looney SW, Wansley JW. An application of the Cox proportional hazards model to bank failure. J Bank Finance 1986; 10(4): 511-531.

23. Saadati M, Bagheri A. Determinants of Iranian youths' marriage age: a parametric survival analysis approach. SDOH 2017; 3(4): 177-185 .

24. Islam MM, Islam MK, Hasan MS, et al. Adolescent motherhood in Bangladesh: trends and determinants. PLoS ONE 2017; 12(11): e0188294.

25. Adebowale SA, Fagbamigbe FA, Okareh TO, et al. Survival analysis of timing of first marriage among women of reproductive age in Nigeria: regional differences. Afr J Reprod Health 2012; 16(4): 95-107.

26. Agaba $P$, Atuhaire LK, Rutaremwa G. Determinants of age at first marriage among women in Western Uganda. Available from URL: https://www.semanticscholar.org/paper/Determinants-of-age-at-first-marriage-among-Women-Agaba-Atuhaire/4295473eb4c73b4b 4afe5fb7ae85941ac8232e8a\#related-papers.

27. Sekine K, Hodgkin ME. Effect of child marriage on girls' school dropout in Nepal: analysis of data from the Multiple Indicator Cluster Survey 2014. PLoS ONE 2017; 12(7): e0180176.

28. McCleary-Sills J, Hanmer L, Parsons J, et al. Child marriage: a critical barrier to girls' schooling and gender equality in education. The Review of Faith \& International Affairs 2015; 13(3): 69-80.

29. Petroni S, Steinhaus M, Fenn NS, et al. New findings on child marriage in sub-Saharan Africa. Ann Glob Health 2017; 83(5-6): 781-790.

30. Kamal SM. Decline in child marriage and changes in its effect on reproductive outcomes in Bangladesh.J Health Popul Nutr 2012; 30(3): 317-330.

31. Paul P. Effects of education and poverty on the prevalence of girl child marriage in India: a district - level analysis. Child Youth Serv Rev 2019; 100: 16-21.

32. Kumchulesi G, Palamuleni M, Kalule-Sabiti I. Factors affecting age at first marriage in Malawi. In: Call for papers. Sixth African Population ConferenceAfrican Population: Past, Present and Future. Ouagadougou - Burkina Faso, 5-9 December 2011: 5-9.

33. Delprato M, Akyeampong K. The effect of early marriage timing on women's and children's health in Sub-Saharan Africa and Southwest Asia. Ann Glob Health 2017; 83(3-4): 557-567.

34. Berliana SM, Kristinadewi PAN, Rachmawati PD, et al. Determinants of early marriage among female adolescent in Indonesia. Int J Adolesc Med Health 2018; 33(1), doi: 10.1515/ijamh-2018-0054.

35. Mehra D, Sarkar A, Sreenath $P$, et al. Effectiveness of a community based intervention to delay early marriage, early pregnancy and improve school retention among adolescents in India. BMC Public Health 2018; 18(1): 1-13.

36. Bhagavatheeswaran L, Nair S, Stone $\mathrm{H}$, et al. The barriers and enablers to education among scheduled caste and scheduled tribe adolescent girls in northern Karnataka, South India: a qualitative study. Int J Educ Dev 2016; 49: 262-270.

Tables: 4

Figures: 1

References: 36

Received: 19.05.2020

Reviewed: 06.06.2020

Accepted: 25.04.2021

Address for correspondence:

Md. Akhtarul Islam, MSc

Faculty of Statistics Discipline

Khulna University

Khulna-9208

Bangladesh

Tel.: +880 1722736875

E-mail: akhtarulstat@ku.ac.bd 